\title{
EFEITOS DA PREMUNIZAÇÃO DA ABÓBORA ‘MENINA BRASILEIRA' COM ESTIRPES FRACAS DO VÍRUS-DO-MOSAICO-DO-MAMOEIRO - ESTIRPE MELANCIA ${ }^{1}$
}

\author{
JORGE ALBERTO MARQUES REZENDE ${ }^{2}$, DAVI ANDRADE PACHECO ${ }^{3}$ e ANTONIO FRANCISCO IEMMA ${ }^{4}$
}

RESUMO - Neste trabalho avaliou-se o efeito da premunização com duas estirpes fracas do vírus-domosaico-do-mamoeiro - estirpe melancia ("papaya ringspot virus - type W", PRSV-W), combinada com a tolerância das plantas, no controle do mosaico e na produtividade da abóbora 'Menina Brasileira'. Testes realizados em casa de vegetação mostraram que as plantas dessa cultivar premunizadas com as estirpes fracas PRSV-W-1 e 2 ficaram totalmente protegidas contra a infecção por uma estirpe severa de Campinas. Em condições de campo avaliou-se comparativamente a produção de plantas premunizadas, infectadas com a estirpe severa de Campinas, e sadias e expostas à infecção natural (controle). A proteção foi medida com base na produção individual das plantas, cujos frutos foram classificados em comerciais e não-comerciais. As plantas premunizadas tiveram uma produção média de frutos comerciais (peso) $33 \%$ superior à daquelas naturalmente infectadas em campo. Quanto ao número de frutos comerciais, o aumento foi da ordem de $50 \%$. A premunização combinada com a tolerância da abóbora 'Menina Brasileira' permitiu um melhor controle do mosaico, com ganhos na produção de frutos comerciais.

Termos para indexação: Cucurbita moschata, controle de doença.

\section{EFFECTS OF CROSS PROTECTION WITH MILD STRAINS OF PRSV-W ON 'MENINA BRASILEIRA' SQUASH}

\begin{abstract}
Cross protection with mild strains combined with tolerance was evaluated for control of papaya ringspot virus - type W (PRSV-W) in squash cultivar 'Menina Brasileira'. Tests carried out in the greenhouse showed that plants premunized with PRSV-W-1 and 2 mild strains were protected against infection with a severe strain of the virus. Protection in the field was evaluated comparing plants premunized with the mild strains, plants infected with severe strains and healthy plants exposed to natural infection (control). Protection index was obtained through yield of marketable and non marketable fruits harvested from individual plants. Average yield (weight) of marketable fruits from protected plants was approximately $33 \%$ higher than that of naturally infected plants in the field. Combination of mild strain protection and tolerance of 'Menina Brasileira' provided a better disease control with a significant increase of fruit yield.

Index terms: Cucurbita moschata, disease control.
\end{abstract}

\section{INTRODUÇÃO}

$\mathrm{O}$ vírus-do-mosaico-do-mamoeiro - estirpe melancia ("papaya ringspot virus - type W", PRSV-W) é uma espécie do gênero Potyvirus, família Potyviridae, que se encontra distribuído por todas

\footnotetext{
${ }^{1}$ Aceito para publicação em 22 de julho de 1998.

2 Eng. Agr., Ph.D., ESALQ/USP, Caixa Postal 09, CEP 13418-900 Piracicaba, SP. E-mail: jamrezen@carpa.ciagri.usp.br

${ }^{3}$ Estudante de Biologia, UNIMEP, Piracicaba. Bolsista da FAPESP.

${ }^{4}$ Licenciado em Matemática, Ph.D., ESALQ/USP.
}

as partes do mundo onde se cultivam cucurbitáceas. No Brasil, este é, aparentemente, o vírus mais comumente encontrado em plantios de abobrinhade-moita (Cucurbita pepo L.) e de outras cucurbitáceas (Kuabara, 1984; Pavan et al., 1989; Lima \& Vieira, 1992). Além da abobrinha-de-moita, as abóboras (C. maxima Duchesne, C. moschata (Duchesne) Duchesne ex Poir.), melão (Cucumis melo L.), melancia (Citrullus lanatus (Thunb.) Matsum. \& Nakai) e pepino (Cucumis sativus L.) também são afetadas por esse vírus, que é eficientemente transmitido por inúmeras espécies de afídeos, de maneira não persistente. 
As medidas de controle geralmente recomendadas para essa virose, especialmente nas espécies que não incorporam genes de resistência ou tolerância, incluem a eliminação de hospedeiras do vírus contidas na vegetação espontânea que ocorre próximas da área de plantio, programas de controle de afídeos vetores com inseticidas, pulverizações com óleos minerais e uso de substâncias refletoras (Adlerz \& Everett, 1968; Chalfant et al., 1977; Brown et al., 1993; Orozco et al., 1994; Summers et al., 1995), que no geral não atingem o objetivo desejado, além de algumas serem economicamente inviáveis em certos casos. Estudos recentes mostram que, no caso da abobrinha-de-moita, que é altamente sensível à virose, a premunização com estirpes fracas do vírus oferece um controle eficiente da doença em campo, com ganhos significativos na produção de frutos comerciais (Rezende, 1996). A premunização de cucurbitáceas também tem se mostrado eficiente para o controle do mosaicoamarelo ("zucchini yellow mosaic virus" - ZYMV) em abobrinha-de-moita, na França, em Taiwan e na Inglaterra (Lecoq et al., 1991; Wang et al., 1991; Walkey et al., 1992), e em melão, na Califórnia, EUA (Perring et al., 1995).

Neste trabalho procurou-se avaliar o efeito da premunização com estirpes fracas do PRSV-W combinada com a tolerância da cultivar de abóbora Menina Brasileira (Kuabara et al., 1987) no controle do mosaico e na produção de frutos comerciais em campo.

\section{MATERIAL E MÉTODOS}

\section{Plantas-teste}

Nos testes conduzidos em casa de vegetação, no Departamento de Fitopatologia da Escola Superior de Agricultura "Luiz de Queiroz", foram utilizadas plantas de abóbora rasteira (Cucurbita moschata) cultivar Menina Brasileira e de abobrinha-de-moita (Cucurbita pepo) cultivar Caserta.

Com o objetivo de ter constante disponibilidade de plantas-teste para as experimentações, as semeaduras foram feitas a intervalos de 15 a 20 dias, em vasos de alumínio contendo terra misturada com composto de matéria orgânica e adubo mineral. $\mathrm{O}$ desbaste foi feito no estádio de folha cotiledonar, deixando-se duas plantas por vaso. Quinzenalmente as plantas foram tratadas com 2-methy-
2-(methylthio)propion-aldehyde-O-(methylcarbamoyl) oxime (Temik) no solo e pulverizadas com Fenarimol (Rubigan) $(0,6 \mathrm{~mL} / \mathrm{L})$ para o controle da mosca-branca (Bemisia tabaci (Gennadius) biótipo B) e do oídio (Sphaerotheca fuliginea (Schlecht. ex Fr.) Poll.), respectivamente. E freqüentemente adubadas com aproximadamente $0,5 \mathrm{~g}$ de sulfato de amônia por vaso.

Para o experimento em campo, as plantas de abóbora 'Menina Brasileira' foram obtidas em bandejas de isopor com 128 células, em condições de casa de vegetação. Usouse o substrato Plantmax, e a semeadura foi feita colocando-se uma semente por célula, numa profundidade aproximada de $0,5 \mathrm{~cm}$. A inoculação das plantas foi feita no estádio de folha cotiledonar. Doze dias depois, as mudas foram transplantadas em campo, em covas previamente preparadas com esterco de curral curtido e adubo mineral, de acordo com as recomendações para a cultura. Foi colocada uma muda por cova, utilizando-se o espaçamento de $3 \times 3 \mathrm{~m}$. As plantas foram irrigadas e receberam os tratos culturais convencionais requeridos pela cultura.

\section{Estirpes do vírus}

Foram utilizadas duas estirpes fracas do PRSV-W, designadas por PRSV-W-1 e PRSV-W-2, selecionadas por Rezende et al. (1994) de bolhas das folhas de abobrinhade-moita com mosaico e uma estirpe do complexo normal coletada na região de Campinas (SP). Todas as estirpes foram mantidas em plantas de abobrinha-de-moita 'Caserta', em condições de casa de vegetação.

\section{Inoculação mecânica}

Os inóculos das estirpes do PRSV-W foram obtidos de folhas de abobrinha-de-moita infectadas, macerando-as em almofariz de porcelana, em presença de tampão de fosfato de potássio $0,02 \mathrm{M}, \mathrm{pH} 7,0$, acrescido de sulfito de sódio na mesma molaridade. As inoculações foram feitas nas folhas previamente polvilhadas com carbureto de silício ("carborundum"), grão 320, friccionando-as com o indicador umedecido na solução de inóculo. Em seguida, as folhas foram lavadas com água para retirar o excesso de abrasivo e de inóculo.

\section{Avaliação da reação de mosaico nas plantas-teste}

A leitura dos sintomas nas plantas-teste geralmente iniciou-se sete dias após a inoculação, tempo suficiente para que ocorresse a invasão sistêmica do vírus. As leituras foram feitas periodicamente, durante o prazo necessário para a conclusão do teste. 
Para avaliação dos sintomas utilizou-se de uma escala de notas de severidade de sintomas, dando nota 1 para plantas com sintomas de mosaico pouco evidentes, sem deformações foliares e bom desenvolvimento; nota 5 para aquelas exibindo sintomas severos de mosaico, deformações foliares intensas, bolhas e desenvolvimento reduzido; e notas 2, 3 e 4 para sintomas intermediários entre os dois extremos. Essa escala de notas foi utilizada em todas as fases de desenvolvimento das plantas.

\section{Teste sorológico de ELISA}

Nos testes em casa de vegetação e em campo houve necessidade de certificar se as plantas inoculadas com as estirpes fracas estavam realmente infectadas. Isto ocorreu pela dificuldade de visualização de sintomas na maioria das plantas inoculadas. A confirmação da infecção foi feita por meio do teste sorológico de ELISA ("Enzyme Linked Immunosorbent Assay"), do tipo PTA ("Plate Trapped Antigen"), com algumas modificações da forma descrita por Mowat \& Dawson (1987). Para esse teste foi utilizado anti-soro contra o PRSV-W obtido do Dr. James Dale, Queensland University of Technology, Austrália.

\section{Teste do efeito protetor das estirpes fracas em casa de vegetação}

Plantas de 'Menina Brasileira' foram inoculadas mecanicamente com as estirpes fracas PRSV-W-1 e 2, no estádio de folha cotiledonar. Dez dias após a inoculação, confirmada a infecção mediante o teste de PTA-ELISA, as plantas foram superinoculadas (desafiadas) com a estirpe severa de Campinas. A superinoculação foi feita mecanicamente em três folhas expandidas do ponteiro. Dez dias depois da primeira superinoculação, as plantas foram novamente desafiadas com a mesma estirpe severa, inoculada mecanicamente em três folhas expandidas do ponteiro, porém diferentes daquelas utilizadas no primeiro desafio. Em todos os testes compararam-se os seguintes tratamentos: a) plantas premunizadas com as estirpes fracas e não desafiadas; b) plantas premunizadas com as estirpes fracas e superinoculadas com a estirpe severa; c) plantas inicialmente sadias, da mesma idade e inoculadas com a estirpe severa, por ocasião da superinoculação; e d) plantas sadias. As plantas do tratamento c serviram de controle dos inóculos das superinoculações e para posterior comparação de sintomas.

Todas as plantas foram mantidas em condições de casa de vegetação, onde foram feitas leituras periódicas de sintomas e testes de recuperação da estirpe da superinoculação, para avaliação do valor protetor das estirpes fra- cas. A recuperação foi feita a partir de folhas inoculadas e/ ou superinoculadas e de folhas novas das plantas-teste. Discos foliares, de $1 \mathrm{~cm}$ de diâmetro, foram retirados de três regiões diferentes das folhas inoculadas ou superinoculadas e das folhas novas das plantas, separadamente. Os inóculos dos discos foliares foram obtidos em almofariz, na presença de tampão de fosfato de potássio. Em seguida foram inoculados mecanicamente em plantas de abobrinha-de-moita 'Caserta'. Cada inóculo foi aplicado em duas plantas de 'Caserta', que permaneceram em casa de vegetação para avaliação de sintomas. Plantas de 'Caserta' apresentam reação diferencial bastante distinta para as estirpes fracas e severa do PRSV-W.

\section{Teste do efeito protetor das estirpes fracas em campo}

As plantas de abóbora 'Menina Brasileira' foram obtidas a partir da semeadura em bandejas em condições de casa de vegetação, em 26/1/95. As plantas de duas bandejas foram premunizadas com as duas estirpes fracas, separadamente, no dia $3 / 2 / 95$, por meio da inoculação mecânica. No mesmo dia um outro grupo de plantas foi inoculado mecanicamente com a estirpe severa de Campinas. Outras plantas permaneceram sadias. No dia 12/2/95 foram coletadas amostras de folhas de todas as plantas premunizadas e realizado um teste de PTA-ELISA, para confirmar a infecção com as estirpes fracas. $\mathrm{O}$ transplante em campo foi feito no dia 15/2/95, colocando-se apenas uma planta positivamente premunizada por cova. Ao redor do campo experimental foram plantadas aproximadamente 100 mudas de abobrinha-de-moita cultivar Caserta inoculadas com a estirpe severa de Campinas, para proporcionar um aumento da fonte de inóculo no local do experimento.

Para fins de avaliação, foram comparados os seguintes tratamentos: 1) plantas premunizadas com a estirpe fraca PRSV-W-1;2) plantas premunizadas com a estirpe fraca PRSV-W-2; 3) plantas inoculadas com a estirpe severa de Campinas no mesmo dia da inoculação de premunização; e 4) plantas sadias e expostas à infecção natural.

$\mathrm{O}$ delineamento experimental foi o de blocos ao acaso, com sete repetições. Cada parcela foi constituída por uma planta, e a parcela do tratamento (4) foi duplicada em todos os blocos.

A colheita teve início no dia 3/4/95. Os frutos foram colhidos em dias alternados, por um período de 24 dias. A colheita foi feita por planta individualmente. Os frutos de cada planta foram pesados em conjunto e classificados em comerciais (frutos de aparência normal) e não comerciais (frutos escurecidos ou deformados). O experimento terminou no dia 29/4/95. Em virtude do emaranhado das ramas das diversas plantas, não foram feitas avaliações de sintomas. 


\section{Análise estatística}

A análise estatística dos dados de produção, no tocante aos pesos dos frutos, foi feita pelo modelo linear de GaussMarkov. Com base no modelo em questão e considerandose que a incidência casual do tospovírus em experimentos de campo sugere a ocorrência de desbalanceamento, foi prevista a utilização do procedimento GLM ("General Linear Model") do Sistema Estatístico SAS ("Statistical Analysis System") disponível na rede ESALQ/USP.

Para detectar possíveis diferenças siginificativas de contrastes entre efeitos dos tratamentos dentro das categorias de frutos comerciais e não comerciais, foi utilizado o comando "estimate" constante no PROC SAS/GLM (Freund et al., 1986; Iemma, 1993).

\section{RESULTADOS E DISCUSSÃO}

\section{Proteção das estirpes fracas em casa de vegeta- ção}

Os resultados de dois testes independentes para avaliar o efeito protetor das estirpes fracas PRSV-W-1 e 2 em plantas de abóbora 'Menina Brasileira' estão apresentados nas Tabelas 1 e 2.

Observações comparativas dos sintomas apresentados pelas plantas premunizadas e pelas inicialmente sadias, que serviram de controle dos inóculos das superinoculações, não permitiram avaliar o efeito protetor das estirpes fracas em abóbora 'Menina Brasileira' (Tabela 1). A maioria das plantas apresentou sintomas considerados fracos (notas 1 e 2), dentro da escala visual de sintomas utilizada. Apenas duas plantas, utilizadas como controles dos inóculos das superinoculações, mostraram sintomas intermediários de mosaico (notas 3 e 4).

Os testes de recuperação da estirpe presente nas folhas inoculadas ou superinoculadas e nas folhas novas das plantas dos diferentes tratamentos permitiram verificar de forma clara que o efeito protetor das estirpes fracas foi positivo (Tabela 2). Todos os inóculos recuperados das folhas superinoculadas e das folhas novas das plantas de abóbora 'Menina Brasileira', premunizadas com as estirpes fracas PRSV-W-1 e 2 e desafiadas com a estirpe severa de Campinas, induziram sintomas fracos de mosaico (nota 1) em plantas-teste de abobrinha-de-moita 'Caserta'. Por sua vez, a maioria dos inóculos recuperados das folhas inoculadas e das folhas novas das plantas que serviram de controle dos inóculos das superinoculações, causou sintomas extremamente severos (nota 5) em 'Caserta', semelhantes aos induzidos pela estirpe severa de Campinas. Exceção de uma planta em que os inóculos recuperados de ambas regiões induziram sintomas fracos de mosaico, sem deformações foliares, semelhante àqueles causados pela estirpe fraca do vírus.

Os resultados dos testes realizados em condições de casa de vegetação foram satisfatórios sob vários aspectos. Em primeiro lugar, verificou-se que as duas estirpes premunizantes não causaram sintomas perceptíveis nas plantas estudadas. Segundo, as estirpes fracas ofereceram proteção total contra a es-

TABELA 1. Reação de plantas de abóbora 'Menina Brasileira' nos testes do efeito protetor de duas estirpes fracas do vírus-do-mosaico-do-mamoeiro - estirpe melancia (PRSV-W), em condições de casa de vegetação.

\begin{tabular}{|c|c|c|c|c|c|c|}
\hline \multirow[t]{2}{*}{ Planta-teste } & \multirow[t]{2}{*}{$\begin{array}{l}\text { № de plantas } \\
\text { testadas }\end{array}$} & \multicolumn{5}{|c|}{$\begin{array}{c}\text { Freqüência de plantas com } \\
\text { as notas de sintomas }{ }^{1}\end{array}$} \\
\hline & & 1 & 2 & 3 & 4 & 5 \\
\hline Premunizada PRSV-W-1 + superinoculada & 8 & 8 & & & & \\
\hline Premunizada PRSV-W-1 (controle) & 4 & 4 & & & & \\
\hline Premunizada PRSV-W-2 + superinoculada & 8 & 8 & & & & \\
\hline Premunizada PRSV-W-2 (controle) & 4 & 4 & & & & \\
\hline Sadia + inóculo $1^{a}$ superinoculação & 8 & 2 & 5 & 1 & & \\
\hline Sadia + inóculo $2^{a}$ superinoculação & 8 & 5 & 2 & & 1 & \\
\hline
\end{tabular}


tirpe severa de Campinas, da qual elas haviam sido inicialmente selecionadas. Finalmente, as avaliações de proteção, por meio de testes de recuperação do inóculo da estirpe da superinoculação, forneceram uma indicação segura de que a proteção foi absoluta, pois em todas as plantas premunizadas e desafiadas só foi possível recuperar a estirpe fraca protetora.

O fato de a superinoculação mecânica não ter sido suficiente para quebrar o efeito protetor pode ser considerado de bastante valor, pois trata-se de um método de inoculação mais drástico do que ocorre no campo, onde a disseminação é por meio de afídeos vetores. É interessante mencionar que estudos anteriores realizados por Rezende et al. (1994), com plantas premunizadas de abobrinha-demoita 'Caserta' em casa de vegetação, indicaram que a proteção também foi eficiente quando a superinoculação foi feita com 10 afídeos virulíferos por planta. Mostraram ainda que a proteção das plantas geralmente ocorreu três dias após a inoculação de premunização. Mais recentemente, Rezende (1996) demonstrou que plantas premunizadas de abobrinha-de-moita também ficaram protegidas contra estirpes severas de Botucatu e de Petrolina, em testes de superinoculação mecânica.
Embora não tenha sido objetivo deste trabalho estudar os mecanismos envolvidos na proteção entre as estirpes do PRSV-W em abóbora 'Menina Brasileira', os resultados dos testes de recuperação da estirpe da superinoculação forneceram uma forte indicação de que a proteção pode estar associada com algum evento no processo inicial de infecção. Isto porque na maioria das folhas superinoculadas só foi possível recuperar a estirpe fraca inicialmente inoculada. Esse resultado é sugestivo de que a estirpe severa superinoculada não foi capaz de infectar aquelas folhas ou, se o foi, ficou restrita a algumas poucas células no local de infecção, impedida de invadir a planta sistemicamente. Mecanismo de proteção associado com o processo inicial de infecção foi demonstrado experimentalmente por Dodds et al. (1985) com estirpes do CMV em plantas de tomateiro (Lycopersicon esculentum Mill. cultivar Rutgers) e por Rezende \& Sherwood (1991) com estirpes do TMV em plantas de fumo (Nicotiana tabacum L. cultivares Samsun e Xanthi). Em ambos os casos os autores demonstraram ainda que o processo envolvido estava relacionado com o impedimento da retirada da capa protéica da estirpe da superinoculação, para iniciar o processo de replicação do ácido nucléico. Isto porque quan-

TABELA 2. Recuperação da estirpe do vírus presente nas folhas (F) inoculadas ou superinoculadas e nas folhas novas de plantas de abóbora 'Menina Brasileira', utilizadas nos testes de proteção com as estirpes fracas do vírus-do-mosaico-do-mamoeiro - estirpe melancia (PRSV-W).

\begin{tabular}{|c|c|c|c|c|c|c|c|}
\hline \multirow[t]{2}{*}{ Planta-teste } & \multirow[t]{2}{*}{$\begin{array}{l}\mathrm{N}^{\mathrm{o}} \text { de } \\
\text { plantas } \\
\text { testadas }\end{array}$} & \multirow[t]{2}{*}{$\begin{array}{l}\text { Origem do } \\
\text { inóculo para } \\
\text { recuperação }\end{array}$} & \multicolumn{5}{|c|}{$\begin{array}{l}\text { Distribuição das estirpes recuperadas } \\
\text { de acordo com a nota de } \\
\text { sintomas em plantas de 'Caserta' }\end{array}$} \\
\hline & & & 1 & 2 & 3 & 4 & 5 \\
\hline Premunizada PRSV-W-1 + & 8 & F. superinoc. & 8 & & & & \\
\hline superinoculada & & F. nova & 8 & & & & \\
\hline Premunizada PRSV-W-1 (controle) & 3 & F. nova & 3 & & & & \\
\hline Premunizada PRSV-W-2 + & 8 & F. superinoc. & 8 & & & & \\
\hline superinoculada & & F. nova & 8 & & & & \\
\hline Premunizada PRSV-W-2 (controle) & 4 & F. nova & 4 & & & & \\
\hline Sadia + inóculo da & 8 & F. inoculada & 1 & & & & 7 \\
\hline $1^{\mathrm{a}}$ superinoculação & & F. nova & 1 & & & & 7 \\
\hline Sadia + inóculo da & 6 & F. inoculada & & & & & 6 \\
\hline $2^{\mathrm{a}}$ superinoculação & & F. nova & & & & & 6 \\
\hline
\end{tabular}


do as plantas previamente infectadas com uma das estirpes do vírus foram superinoculadas apenas com o ácido nucléico (RNA) da estirpe desafiante, esta infectou as folhas superinoculadas. Ainda mais, no trabalho de Rezende \& Sherwood (1991) verificouse que após multiplicar-se nas folhas superinoculadas a estirpe desafiante invadiu as plantas sistemicamente. Modelo desse tipo poderia ser utilizado para estudar se a proteção oferecida pelas estirpes fracas do PRSV-W em espécies de Cucurbita também está associada com o impedimento da retirada da capa protéica da estirpe severa superinoculada.

\section{Efeito protetor das estirpes fracas em condições de exposição em campo}

Antes de apresentar os resultados do teste de proteção com plantas premunizadas de abóbora 'Menina Brasileira' expostas em condições de campo, é necessário mencionar que no experimento ocorreu a incidência indesejável de uma possível nova espécie do gênero Tospovirus, da família Buniaviridae (Rezende et al., 1997), que prejudicou parcialmente as avaliações. As plantas de abóbora 'Menina Brasileira' infectadas por esse vírus apresentam um mosaico-amarelo, rugosidade do limbo foliar, enrolamento dos bordos das folhas para cima e redução dos internódios. Para facilitar o diagnóstico dessa infecção, foi feita a indexação biológica em plantas de Datura stramonium L., que reagem com sintomas locais e sistêmicos bastante característicos. Os resultados da indexação bioló- gica indicaram que oito, das 35 plantas do campo, estavam infectadas no final do experimento. Para fins de análise, foram desconsideradas as produções totais de todas as plantas que testaram positivo para esse tospovírus.

$\mathrm{O}$ efeito protetor das estirpes fracas do PRSV-W em plantas de abóbora 'Menina Brasileira' em condições de campo foi estudado apenas com base na produção de frutos, cujos resultados estão apresentados na Tabela 3 e ilustrados na Fig. 1.

Verificou-se que as plantas de 'Menina Brasileira', quando infectadas com a estirpe normal do vírus no estádio de folha cotiledonar, tiveram uma redução bastante acentuada (62\%) na produção de frutos comerciais (peso), quando comparada à daquelas que foram naturalmente infectadas em campo. As plantas premunizadas com as duas estirpes fracas tiveram um ganho na produção, em relação às plantas infectadas naturalmente em campo. A análise de variância e as estimativas dos contrastes entre os tratamentos indicaram que não houve diferença significativa entre as produções de frutos comerciais das plantas premunizadas com as duas estirpes fracas. Também não foi detectada diferença estatística significativa entre as produções dessas plantas e as daquelas infectadas naturalmente com o complexo normal em campo. No entanto, a produção de frutos comerciais dos três tratamentos diferiu significativamente da produção das plantas inoculadas com a estirpe severa de Campinas no estádio cotiledonar. A mesma interpretação é válida para a produção de frutos não comerciais dos quatro tratamentos.

TABELA 3. Número e peso total de frutos comerciais e não comerciais colhidos de abóbora 'Menina Brasileira', no período de 03/04/95 a 27/04/95, no experimento de proteção sob condições de exposição em campo. Valores entre parêntesis representam a média por planta ${ }^{1}$.

\begin{tabular}{|c|c|c|c|c|c|}
\hline \multirow[t]{2}{*}{ Tratamento } & \multirow{2}{*}{$\begin{array}{l}\text { Número } \\
\text { de plantas } \\
\text { avaliadas }\end{array}$} & \multicolumn{2}{|c|}{ Frutos comerciais } & \multicolumn{2}{|c|}{ Frutos não comerciais } \\
\hline & & Número & Peso (kg) & Número & Peso $(\mathrm{kg})$ \\
\hline Premunizada com PRSV-W-1 & 4 & $102(25,5)$ & $37,6(9,2) \mathrm{a}$ & $26(6,5)$ & $12,1(3,0) \mathrm{a}$ \\
\hline Premunizada com PRSV-W-2 & 6 & $142(23,7)$ & $62,8(10,5) \mathrm{a}$ & $36(6,0)$ & $15,9(2,6) \mathrm{a}$ \\
\hline Inoculada com isolado normal & 6 & $38(6,3)$ & $16,5(2,8) \mathrm{b}$ & $19(3,2)$ & $7,2(1,2) b$ \\
\hline Controle (infecção natural) & 11 & $181(16,4)$ & $81,9(7,4) \mathrm{a}$ & $29(2,6)$ & $12,5(1,1) \mathrm{a}$ \\
\hline
\end{tabular}

${ }^{1}$ Médias seguidas da mesma letra não diferem a $1 \%$ de probabilidade.

2 Plantas que não foram infectadas com o tospovírus. 
Considerando-se que a produção de frutos comerciais (peso) das plantas naturalmente infectadas representa $100 \%$ da sua capacidade produtiva, as plantas premunizadas com a estirpe fraca PRSV-W-1 produziram $24 \%$ a mais, enquanto aquelas premunizadas com a estirpe fraca PRSV-W-2 tiveram um ganho de 41,8\%. Em termos de número de frutos comerciais os ganhos foram da ordem de $55,4 \%$ e $44,5 \%$, respectivamente. Sendo a abóbora 'Menina Brasileira' tolerante ao mosaico causado pelo PRSV-W (Kuabara et al., 1987), sugere-se que esse incremento na produção pode estar associado com o melhor controle da doença obtido com a combinação dessa característica genética das plantas com a premunização.

Do total de frutos colhidos das plantas premunizadas com as duas estirpes fracas e daquelas inoculadas com a estirpe normal no estádio cotiledonar, 20 a $25 \%$ foram considerados não comerciais. Por outro lado, as plantas que foram naturalmente infectadas em campo tiveram apenas $7,4 \%$ do total de frutos produzidos classificados

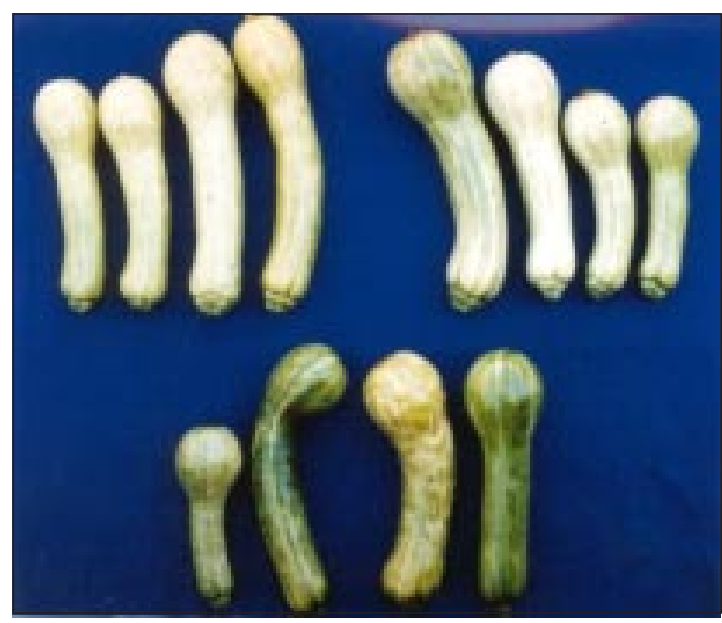

FIG. 1. Frutos de plantas de Cucurbita moschata cv. Menina Brasileira naturalmente infectadas com a estirpe normal do PRSV-W (canto superior esquerdo); frutos de plantas premunizadas com as estirpes fracas (canto superior direito) e frutos de plantas inoculadas com a estirpe normal de Campinas, no estádio cotiledonar (embaixo). nessa categoria. Mesmo que seja descontado o aumento na produção de frutos não comerciais, as plantas premunizadas ainda apresentam um ganho significativo na produção de frutos comerciais, que viabiliza a utilização da técnica. É importante lembrar que parte das plantas inicialmente sadias pode ter sido naturalmente infectada com uma das estirpes fracas do vírus, transmitida por afídeos. Não foi feito teste de indexação no final do experimento para verificar o número de plantas que estariam infectadas com uma das estirpes fracas do vírus. A seleção de estirpes fracas que causem menos prejuízos à qualidade dos frutos produzidos por plantas premunizadas dessa variedade poderá minimizar esse problema e proporcionar ganhos maiores na produção.

Para que as estirpes fracas do PRSV-W possam ser utilizadas pelos agricultores, é necessário o estabelecimento de um procedimento simples, rápido e eficiente para a inoculação (premunização) massal das plantas. Yeh et al. (1988) premunizaram eficientemente mudas de mamoeiro com uma estirpe fraca do "papaya ringspot virus - type P" (PRSV-P), aplicando o inóculo com uma pistola para pintura, com pressão de $4-6 \mathrm{~kg} \mathrm{~cm}^{-2}$. O inóculo da estirpe fraca foi diluído na proporção de $1 \mathrm{~g}$ de tecido para $20 \mathrm{~mL}$ de tampão. Perring et al. (1995) verificaram que uma suspensão de $10 \%$ (g de tecido/mL de tampão) da estirpe fraca do ZYMV, aplicada em plantas de melão, com pressão de $2,1 \mathrm{~kg} \mathrm{~cm}^{-2}$, resultou numa infeção aproximada de $80 \%$. Estudos realizados para a inoculação massal de plantas de abobrinha-de-moita com a estirpe fraca PRSV-W-1, aplicada com uma pistola para pintura, mostraram resultados distintos daqueles relatados por Perring et al. (1995). Inóculos diluídos $1: 50,1: 100,1: 150$ e $1: 200$ e aplicados sob pressão de $2,8 \mathrm{~kg} \mathrm{~cm}^{-2}$, a uma distância de $5 \mathrm{~cm}$ das plantas da bandeja, resultaram em 100\% de infecção. Devido ao baixo custo da obtenção do inóculo e do processo de inoculação, para fins comerciais tem-se recomendado a utilização da diluição de 1:25 para garantir o máximo de eficiência.

\section{CONCLUSÕES}

1. As estirpes fracas do PRSV-W protegem eficientemente plantas de abóbora 'Menina Brasilei- 
ra' contra a infecção e a manifestação da estirpe severa utilizada na superinoculação.

2. A premunização combinada com a tolerância ao mosaico encontrada na cultivar Menina Brasileira permite ganhos significativos na produção de frutos comerciais.

\section{REFERÊNCIAS}

ADLERZ, W.C.; EVERETT, P.H. Aluminum foil and white polyethylene mulches to repel aphids and control watermelon mosaic. Journal of Economic Entomology, v.61, n.5, p.1276-1279, Oct. 1968.

BROWN, J.E.; DANGLER, J.M.; WOODS, F.M.; TILT, K.M.; HENSHAW, M.D.; GRIFFEY, W.A.; WEST, M.S. Delay in mosaic virus onset and aphid vector reduction in summer squash grown on reflective mulches. HortScience, v.28, n.9, p.895-896, Set. 1993.

CHALFANT, R.B.; JAWORSKI, C.A.; JONHSON, A.W.; SUMNER, D.R. Reflective film mulches, millet barriers, and pesticides effect on watermelon mosaic virus, insects, nematodes, soil borne fungi, and yield of yellow summer squash. Journal of the American Society for Horticultural Science, v.102, n.1, p.1115, Jan. 1977.

DODDS, J.A.; LEE, S.Q.; TIFFANY, M. Cross protection between strains of cucumber mosaic virus: effect of host and type of inoculum on accumulation of virions and double-stranded RNA of the challenge strain. Virology, v.144, n.2, p.301-309, July 1985.

FREUND, R.J.; LITTELL, R.C.; SPECTOR, P.C. SAS system for linear models. Cary, NC: SAS Institute, 1986. 210p.

IEMMA, A.F. Análisis de varianza con datos desbalanceados: Simpósio de Estadistica. Santafé de Bogotá, Colombia: Universidad Nacional de Colombia, 1993. 102p.

KUABARA, M.Y. Reação de abobrinha (Cucurbita moschata Duchesne) ao vírus do mosaico da melancia Raça-1 (WMV-2). Piracicaba: USP-ESALQ, 1984. 68p. Dissertação de Mestrado.

KUABARA, M.Y; SALCEDO, M.J.G.; COSTA, C.P. Fontes de resistência ao vírus do mosaico da melancia-1 (WMV-1) em abóbora. Horticultura Brasileira, v.5, n.2, p.20-21, nov. 1987.
LECOQ, H.L.; LEMAIRE, J.M.; WIPF-SCHEIBEL, C. Control of zucchini yellow mosaic virus in squash by cross protection. Plant Disease, v.75, n.2, p.208211, Feb. 1991.

LIMA J.A.A.; VIEIRA, A.C. Distribuição do vírus do mosaico da abóbora em municípios cearenses e gama de hospedeiros de um isolado. Fitopatologia Brasileira, v.17, n.1, p.112-114, abr. 1992.

MOWAT, W.P.; DAWSON, S. Detection of plant viruses by ELISA using crude sap extracts and unfractionated antisera. Journal of Virological Methods, v.15, p.233-247, 1987.

OROZCO, S.M.; LOPEZ, A.O.; PEREZ, Z.O.; DELGADILLO, S.F. Effect of transparent mulch, floating row covers and oil sprays on insect populations, virus disease and yield of cantaloup. Biological Agriculture and Horticulture, v.10, n.4, p.229-234, 1994.

PAVAN, M.A.; CARVALHO, M.G.; FERNANDES, J.J. Distribuição do vírus do mosaico da melancia (papaya ringspot virus-W), nas principais regiões produtoras de pepino (Cucumis sativus) e abobrinha (Cucurbita реро) de Minas Gerais. Fitopatologia Brasileira, v.14, n.1, p.84-85, abr. 1989.

PERRING, T.M.; FARRAR, C.A.; BLUA, M.J.; WANG, H.L.; GONSALVES, D. Cross protection of cantaloupe with a mild strain of zucchini yellow mosaic virus: effectiveness and application. Crop Protection, v.14, n.7, p.601-606, July 1995.

REZENDE, J.A.M. Premunização de duas espécies e um híbrido de Cucurbita para o controle do mosaico causado pelo vírus do mosaico do mamoeiro - estirpe melancia. Piracicaba: USP-ESALQ, 1996. 88p. Tese de Livre Docência.

REZENDE, J.A.M.; GALLETI, S.R.; POZZER, L.; RESENDE, R.O.; DE ÁVILA, A.C.; SCAGLIUSI, S.M.M. Incidence, biological and serological characteristics of a tospovirus infecting experimental fields of zucchini in São Paulo State, Brazil. Fitopatologia Brasileira, v.22, n.1, p.92-95, mar. 1997.

REZENDE, J.A.M.; SHERWOOD, J.L. Breakdown of cross protection between strains of tobacco mosaic virus due to susceptibility of dark green areas to superinfection. Phytopathology, v.81, n.12, p.14901496, Dec. 1991 
REZENDE, J.A.M.; YUKI, V.A.; VEGA, J.; SCAGLIUSI, S.M.M.; BORBA, L.F.; COSTA, A.S. Isolados fracos do potyvirus causador do mosaico da abobrinha presentes em bolhas que atuam na premunização. Fitopatologia Brasileira, v.18, n.1, p.55-61, mar. 1994.

SUMMERS, C.G.; STAPLETON, J.J.; NEWTON, A.S.; DUNCAN, R.A.; HART, D. Comparison of sprayable and film mulches in delaying the onset of aphidtransmitted virus diseases in zucchini squash. Plant Disease, v.79, n.11, p.1126-1131, Nov. 1995.

WALKEY, D.G.A.; LECOQ, H.L.; COLLIER, R.; DOBSON, S. Studies on the control of zucchini yellow mosaic virus in courgettes by mild strain protection. Plant Pathology, v.41, p.762-771, 1992.

WANG, H.-L.; GONSALVES, D.; PROVVIDENTI, R.; LECOQ, H.L. Effectiveness of cross protection by mild strain of zucchini yellow mosaic virus in cucumber, melon, and squash. Plant Disease, v.75, n.2, p.203207, Feb. 1991

YEH, S.-D.; GONSALVES, D.; WANG, H.-L.; NAMBA, R.; CHIU, R.-J. Control of papaya ringspot virus by cross protection. Plant Disease, v.72, n.5, p.375380, May 1988. 